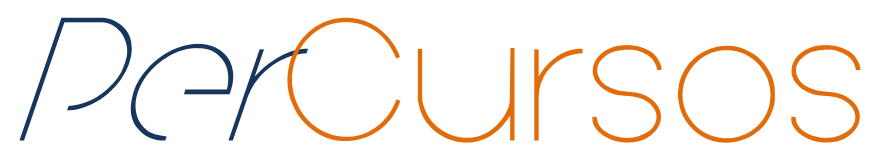

\title{
Migrações e trabalho na Europa: a presença de ibero-americanos e suas especificidades
}

ZANIN, Valter; MATTIAZZI, Giulio. Migrazione, Lavoro, Impresa: Tra America Latina ed Europa. Torino: Harmattan, 2011.

\author{
Eloisa Rosalen \\ Mestranda em História pela Universidade Federal de \\ Santa Catarina - Brasil. \\ eloisarosalen@hotmail.com
}

\section{Para citar este artigo:}

ROSALEN, Eloisa. Migrações e trabalho na Europa: a presença de ibero-americanos e suas especificidades. Revista PerCursos. Florianópolis, v. 14, n.26, p. 390 - 397. jan./jun. 2013. 
O livro Migrazione, lavoro, impresa: Tra America Latina ed Europa, publicado pela Editora Harmattan e organizado pelos sociólogos Valter Zanin e Giulio Mattiazzi, traz alguns estudos sobre a presença de imigrantes ibero-americanos na Europa e, mais especificamente, na Itália. Segundo os organizadores, trata-se de uma escolha face ao aumento da presença destes imigrantes, crescente em comparação ao que foi levantado por Isabel Yépez del Castilho e Gioconda Herrera, em 2007, em alguns países como Portugal, Espanha e Itália. O que trouxe uma modificação nos perfis sociais e nos circuitos de circulação (p. 9) destes sujeitos.

Para os organizadores, o cenário do livro é diferente daquele das duas obras escritas anteriormente acerca da presença dos latino-americanos (AMBROSINI; PALMAS, 2005; e CASTILLO; HERRERA, 2007), que se dedicaram a construções identitárias, a redes transnacionais e familiares, entre outras. Já a obra analisada, para eles, mostra questões relativas ao trabalho, entendido em sentido amplo, nele compreendidas atividades como as de empreendedorismo. Temática essa, juntamente com a ideia de restrição e precarização dos direitos trabalhistas, que vem sendo pesquisada pelos organizadores na Universidade de Pádova.

Advertem, na introdução, que os artigos mantêm sempre uma dimensão comparativa, tanto entre as várias nacionalidades de imigrantes, quanto em relação às suas trajetórias. Além de situar ao leitor que é um tanto problemático tratar como homogêneos os fluxos e a presença dos imigrantes do centro e do sul da América, na Europa.

A obra aqui analisada se divide em duas partes: a primeira é dedicada às migrações entre a América-Latina e a Europa, numa perspectiva europeia; a segunda traz artigos com aspectos relativos à presença dos ibero-americanos na Itália. Alguns dos capítulos foram discutidos em uma prévia no seminário Migrazione, lavoro, impresa tra America Latina ed Europa, realizado em 2009; outros foram escritos a partir de convites dos organizadores, independentemente do evento. 
No primeiro capítulo, denominado Le nuove migrazioni latinoamericane: analisi e prospettive, Isabel Yépez del Castillo traça uma perspectiva geral a respeito das migrações latino-americanas para a Europa. Faz um histórico destes deslocamentos desde os anos 70 até a atualidade, argumenta sobre as relações globais com as cadeias de trabalho de cuidados que existem atualmente, e, por último, levanta uma agenda de possíveis pesquisas.

Por sua vez, Beatriz Padilla, em L'immigrazione latinoamericana in Portogallo. Dalla visibilità brasiliana all'invisibilità degli isponofoni, compara brasileiros e hispanoamericanos no que diz respeito as suas inserções no mercado de trabalho em Portugal. A autora discute o caso desses imigrantes a partir de algumas teses explicativas, entre elas: a da colonização, a da ligação de sangue (descendência), a da globalização, entre outras.

Giuditta Mainardi, em A ritmo latino: una panoramica sulla migrazione sudamericana in Svizzera, apresenta, a respeito dos latinos na Suíça, um debate acerca de seus projetos migratórios e de sua inserção profissional, procurando relacionar os objetivos de cada um com o tempo de permanência no país analisado, sem esquecer as restrições estruturais presentes nessa sociedade.

Cabe destacar que nestes três textos estão presentes a temática da feminização na imigração latina e análises de gênero. Temática essa essencial na atualidade, na busca pela equidade de gênero, e que muitas vezes não é mencionada, esquecida ou tida como não importante. Isabel Yépez del Castillo assinala a necessidade de pesquisas futuras sobre a temática; já Beatriz Padilla apresenta os quadros de comparações no caso de Portugal; enquanto Giuditta Mainardi destaca a feminização da imigração na Suíça.

Luiz Garzón Guillén, em L'immigrazione latinoamericana qualitifacata in Europa e l'effeto specchio. Note a partire dai casi catalano, italiano e belga, ao falar sobre migrações de profissionais qualificados, faz uma comparação entre argentinos e equatorianos (com seus perfis de qualificação). O autor aponta as situações ligadas às legislações políticomigratórias e às dinâmicas associadas ao trabalho, que beneficiam ou dificultam o processo de integração nos países analisados. 
No último capítulo desta parte, denominado Immigrazione e impresa nell'ordinamento giuridico brasiliano, Alfredo Calderale faz uma gênese da atual norma legislativa brasileira, com uma análise jurídica que relaciona o direito privado às legislações imigratórias. Ele toma como início de seus estudos o século XVIII, chegando até a legislação promulgada em 2009.

Na segunda parte do livro, o capítulo Dall'Argentina e dal Brasile verso l'Italia (19982009): le nuove migrazioni d'italo-discendenti e la costruzione dell'italianità contemporanea, de Mélanie Fusaro, é dedicado à construção de uma italianidade contemporânea dos ítalo-brasileiros e ítalo-argentinos. A autora analisa essa construção relacionada ao processo de aquisição de cidadania italiana e à experiência migratória ligada a tal processo. Destaco que a pesquisadora tem uma preocupação histórica a respeito, relacionando a grande emigração italiana (século XIX) com o retorno dos ítalodescendentes à Itália (século XX), o que apresenta a especificidade do caso dos ítalodescendentes na Itália.

Os pesquisadores brasileiros Weber Soares, Dimitri Fazito, Denise Helena França Marques e Sergio D. Faria, em Aspetti socio-demografici delle migrazioni di ritorno dall'Italia al Brasile (1986-2000), argumentam sobre a migração de retorno de brasileiros que estavam na Itália, a partir dos dados do Censo de 1986-1991 e 1995-2000. Eles comentam sobre os seus perfis e o contexto de adaptação, e comparam a inserção dos retornados com a dos atuais imigrantes italianos no Brasil.

Este capítulo é um resultado preliminar sobre a pesquisa que este grupo vem realizando em conjunto com Valter Zanin e Giulio Mattiazzi. Acentuo que se trata de uma tentativa muito interessante a fim de mensurar os deslocamentos dos ítalo-brasileiros com cidadania italiana (que não entram nos dados estatísticos italianos, como o Dossier (aritas e o Istat $\left.{ }^{1}\right)$, e são dados importantes para verificar a situação dos retornados ao Brasil.

Alessandra Ciurlo, em I latinoamericani in Italia: dalla presenza all'imprenditoria, analisa os dados do Istat relativos aos imigrantes latino-americanos. Ela se dedicou a

\footnotetext{
${ }^{1}$ Instituto Nacional de Estatística da Itália.
} 
correlacionar os dados gerais sobre a presença destas pessoas no território italiano, como a evolução da presença latina, a distribuição territorial - tanto dos imigrantes como das empresas - com os motivos de permanência/estada na Itália (através dos permessi di soggiorno).

Seu objetivo, porém, foi analisar empresas autônomas, constituídas por estes imigrantes na Itália, os quais, segundo a autora, são os que - dentro de cada nacionalidade - estão mais bem radicados no território nacional. Para isso, ela comparou dados entre as sete maiores nacionalidades (Peru, Brasil, Equador, Argentina, Colômbia, Cuba e Venezuela) das quais faziam parte os proprietários de empresas.

Alessandara Ciurlo, ao falar da presença de ibero-americanos ou de suas empresas, argumenta que a descendência italiana tem um papel muito interessante. Para ela, o fato desses sujeitos e suas respectivas empresas estarem em grande número localizados no Vêneto e nas regiões do Norte da Itália não é mero acaso e não se justifica somente pelas questões econômicas, mas se relaciona com sua ascendência, uma vez que seus antepassados partiram destas regiões.

No capítulo de Giulio Mattiazzi, em La migrazione latinoamericana nel Veneto: approci socio-demografici al caso brasiliano, podemos ver uma comparação entre o caso brasileiro e o de outros latino-americanos presentes na Itália atualmente. Ele analisa o problema sobre a estimativa do número de brasileiros, os motivos de concessão do permesso di soggiorno ${ }^{2}$, os procedimentos requeridos para o reconhecimento da cidadania italiana aos ítalo-descendentes, e às requisições feitas na Itália.

Saliento que este autor levanta o debate da transmissão da cidadania italiana a um número relevante de descendentes espalhados pelo mundo e que, atualmente, na Itália isso é negado aos filhos de estrangeiros nascidos nesse território nacional. Apesar de se tratar de um tema extremamente pertinente para a atualidade, está ausente no questionamento do autor um debate histórico sobre a transmissão de cidadania italiana,

\footnotetext{
${ }^{2}$ Permesso di soggiorno é o documento de permanência legal de longa duração (superior a três meses, no caso de brasileiros) solicitado pelo imigrante, a partir do visto emitido pelo consulado de origem, a começar do momento de entrada na Itália e com um máximo de oito dias de limite de prazo.
} 
o que negligenciou um respectivo exame do contexto e das legislações que foram se estabelecendo ao longo do século XX.

Por último, Valter Zanin, no texto Processi istituzionali di etnicizzazione dei flussi migratori e profili socio-professionali degli immigrati centro-sudamericani in Italia: Studio comparato sui discendenti d'italiani, analisa os perfis socioprofissionais de imigrantes donos de empresas na Itália, na região do Vêneto, comparando os ibero-americanos descendentes de italianos (que possuem cidadania) com aqueles que não têm 'origem'. Ele se preocupa, sobretudo, com a inserção no trabalho empreendedor dos ítalobrasileiros, e a partir da comparação, acaba desenhando as características gerais sobre as atividades desenvolvidas por eles.

Para este autor, existe um processo de "etnicização" dos fluxos migratórios por parte do Estado italiano que, baseado na Lei $n^{\circ}$ 91, de 1992, transmite a cidadania aos descentes de emigrantes italianos e limita a todos os outros o acesso a ela. Assim, a aquisição da cidadania italiana se torna um mecanismo facilitador, tanto para os deslocamentos da Europa, quanto para a entrada em países com maior nível de exigência, como os Estados Unidos.

Apesar de não ser o argumento principal do autor, cabe comentar que ele reduz a questão da transmissão da cidadania a uma mera relação entre aquisição e a facilidade de deslocamento. Por isso, deixa de mencionar outras questões, como o número

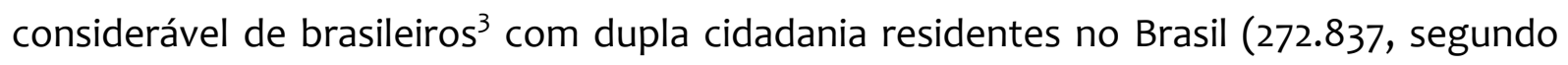
Licata e Pittau, 2011), como também não menciona que nem todas essas pessoas - apesar de possuidoras desse facilitador - têm a pretensão de migrar.

De modo geral, esta obra, organizada por Valter Zanin e Giulio Mattiazzi apresenta quadros gerais sobre a presença dos ibero-americanos localizados na Europa. Apesar de se limitar à Itália, à Suíça, à Espanha, à Bélgica e a Portugal, delineia as especificidades destas migrações, alguns aspectos gerais sobre a Ibero-América e questões relativas ao trabalho.

\footnotetext{
${ }^{3}$ Cabe comentar que estes são números absolutos, já que não existe distinção entre os que têm cidadania, por serem descendentes de imigrantes italianos do século XIX, e imigrantes contemporâneos, residentes no Brasil.
} 
Desta forma, torna-se leitura obrigatória para os estudiosos que pretendem se dedicar aos deslocamentos dos sujeitos situados nestas áreas territoriais, muito embora as temáticas abordadas no livro não consigam - em alguns momentos - relacionar a agência dos sujeitos que se deslocaram e suas respectivas escolhas individuais (salvo em alguns capítulos, entre eles o da Giuditta Mainardi) com os contextos de cada país, região, etc.

\section{Referências}

AMBROSINI, Maurizio; PALMAS, Luca Queirolo (Org.). I latinos alla scoperta dell' Europa. Milão: Franco Angeli, 2005.

CASTILLO, Isabel Yépez del; HERRERA, Gioconda (Org.). Nuevas migraciones latinoamericanas a Europa: balances y desafíos. Quito: Flacso-sede Ecuador, 2007.

LICATA, Delfina; PITTAU, Franco (Org.). Rapporto Italiani nel Mondo 2010. Roma: Caritas/Migrantes. 2010. 
Universidade do Estado de Santa Catarina - UDESC Centro de Ciências Humanas e da Educação - FAED

Revista PerCursos

Volume 15 - Número 28 - Ano 2014 revistapercursos@gmail.com 